\title{
POLYURIA IN PAROXYSMAL TACHYCARDIA AND PAROXYSMAL ATRIAL FLUTTER AND FIBRILLATION
}

\author{
BY
}

\section{PAUL WOOD}

\begin{abstract}
When Paul Wood spoke about this to the British Cardiac Society in 1961, we were impressed by the originality of his work on a subject that so many had noticed but failed to investigate. A few months before his death in July 1962, when I asked him if his paper was ready for the journal, he said that he had not yet been able to get all the evidence he hoped for to establish the full explanation. Unfortunately, he had not the time to complete

- this. I have, therefore, tried to set out as clearly as possible the stage that he had reached.
\end{abstract}

Maurice Campbell

For some nine years (since 1952) I have observed that a remarkable polyuria may accompany paroxysmal tachycardia.

The phenomenon seems little known. Thus Paul White (1951) says "An occasional symptom during or following paroxysmal tachycardia is increased frequency or increased amount of urination, doubtless a nervous reflex." Friedberg in his first edition (1949) states that "there may be polyuria at the termination of the paroxysm," but changes this in his second edition (1956) to "during or at the termination of the paroxysm." Katz and Pick (1956) in a book devoted to the arrhythmias say "Frequency of urination is an unusual symptom in short attacks, but polyuria is often seen after the termination of long ones." I could find no other mention of polyuria relating to paroxysmal tachycardia in any textbook of cardiology written in the English language-except in the second edition of my own book (1956) where it says "If the heart is normal, there is usually a remarkable degree of polyuria during the attack."

At that time the mechanism of the diuresis was obscure. In 1955 in a letter to Dr. Carter about a woman of 46 with paroxysmal tachycardia associated with the Wolff-Parkinson-White syndrome, I wrote "She has had the attacks off and on for six months and is now getting them very frequently, even several a week, and sometimes they last up to 24 hours. The palpitations are fast, regular, and of abrupt onset: the offset does not seem to her abrupt, but she is aware when the attack ends. Twenty minutes after the onset polyuria begins and she passes large quantities of water every 20 minutes throughout the attack. This state of functional transient diabetes insipidus is characteristic of paroxysmal tachycardia with a good cardiac output, but we have no idea whether the effect is related to the renal blood flow or whether it is due to suppression of the anti-diuretic hormone of the pituitary for reasons that are not understood."

I decided to let the matter rest until I had collected sufficient clinical data to be worth analysing, in the hope that natural experiments would point the way to the solution of the problem. These data are now available and I would like to present them to you.

In the first place three statements may be made with confidence.

(1) Polyuria may occur with any form of paroxysmal arrhythmia with rapid heart rate (but so far not with paroxysmal heart block or with paroxysmal nodal rhythm).

(2) Polyuria does not usually occur in short attacks lasting between 5 and 20 minutes. I have found no evidence of it in 12 such cases where the average duration of the paroxysms was 10 minutes.

(3) Polyuria is not associated with paroxysmal arrhythmias with heart rates less than 110 a minute ( 6 cases of paroxysmal atrial fibrillation with rates between 84 and 100 a minute). 
In view of these facts the material presented is limited to 64 cases of primary paroxysmal arrhythmia having a heart rate of 120 or more a minute for at least half an hour, in which the presence or absence of polyuria was established.

\section{Influence of some Clinical Features on the Polyuria}

Nature of the Arrhythmia. Paroxysmal lone atrial fibrillation is more likely to provoke polyuria than any other rhythm change with the possible exception of flutter (Table I). In both these

TABLE I

Incidence of Polyuria in Various Paroxysmal Arrhythmias

\begin{tabular}{l|c|c|c}
\hline $\begin{array}{c}\text { Nature of } \\
\text { arrhythmia }\end{array}$ & $\begin{array}{c}\text { No. of } \\
\text { cases }\end{array}$ & $\begin{array}{c}\text { No. with } \\
\text { polyuria }\end{array}$ & Percentage \\
\hline Atrial fibrillation & 19 & 13 & 68 \\
Atrial flutter & 8 & 5 & 63 \\
Atrial tachycardia & 8 & 2 & 25 \\
Nodal tachycardia & 2 & 0 & $\overline{50}$ \\
W.P.W. syndrome & 6 & 3 & 50 \\
Uncertain & 16 & 8 & 40 \\
Ventricular tachycardia & 5 & 2 & $51 \cdot 5$ \\
\hline Total & 64 & 33 & \\
\hline
\end{tabular}

arrhythmias it occurred in over 60 per cent of the cases. Particularly interesting is the low rating of paroxysmal atrial tachycardia in this respect, for polyuria occurred in only 25 per cent of these. In the whole series, polyuria occurred in just over 50 per cent of the paroxysms at a rate of 120 or more a minute that lasted at least half an hour. [Whether this is true of all such paroxysms or whether these patients were rather older than usual is uncertain. Only 22 of the 64 subjects have been found listed: 11 of these with paroxysmal fibrillation or flutter had an average age of 53 years, and the other 11 with paroxysmal tachycardia had an average age of 37 years. The former figure is probably the usual age of patients with paroxysmal fibrillation, but the latter is perhaps rather older than the usual age of those with paroxysmal tachycardia. M.C.]

Influence of Heart Rate, Posture, and the Type of Heart Disease. Polyuria may be associated with any heart rate between 120 and 280 beats a minute, whatever the nature of the arrhythmia (Table II). The means of the slowest and fastest rates during attacks showed no difference between those who had and those who had not polyuria.

TABLE II

The Heart Rate in Paroxysmal Arrhythmias with and without Polyuria

\begin{tabular}{l|c|c}
\hline \multicolumn{1}{c|}{ Arrhythmia } & $\begin{array}{c}\text { With } \\
\text { polyuria }\end{array}$ & $\begin{array}{l}\text { With no } \\
\text { diuresis }\end{array}$ \\
\hline Atrial fibrillation & $120-160$ & $140-160$ \\
Atrial flutter & $135-150$ & $140-160$ \\
Atrial tachycardia & $150-250$ & $130-300$ \\
Nodal tachycardia & $150-230$ & $140-180$ \\
W.P.W. syndrome & $190-280$ & $150-240$ \\
Uncertain & $150-200$ & $150-160$ \\
Ventricular tachycardia & & \\
\hline
\end{tabular}

Diuresis was more profuse and started earlier in nocturnal attacks than in paroxysms occurring during the day, provided the patient did not lie down in the attack that occurred in the day time.

The relation between polyuria and some other symptoms in ten patients with paroxysms and organic heart disease is shown in Table III. Paroxysmal atrial fibrillation did not provoke polyuria 
TABLE III

Relation of Polyuria and Other Symptoms in 10 Cases With Organic Heart Disease

\begin{tabular}{|c|c|c|c|c|c|c|c|c|}
\hline \multirow{2}{*}{ Disease } & \multirow{2}{*}{ No. } & \multirow{2}{*}{$\begin{array}{l}\text { Grade } \\
\text { of } \\
\text { severity }\end{array}$} & \multirow{2}{*}{ Arrhythmia } & \multirow{2}{*}{ Rate } & \multicolumn{3}{|c|}{ Symptom in attack } & \multirow{2}{*}{$\begin{array}{l}\text { Poly- } \\
\text { uria }\end{array}$} \\
\hline & & & & & A.P. & Sync. & H.F. & \\
\hline Aortic stenosis & 3 & $\begin{array}{l}\text { Mild } \\
\text { Moderate } \\
\text { Severe }\end{array}$ & Uncertain & $\begin{array}{c}? \\
180 \\
?\end{array}$ & $\begin{array}{l}+ \\
+ \\
+\end{array}$ & $\bar{z}$ & $\begin{array}{l}- \\
-\end{array}$ & $\begin{array}{l}- \\
-\end{array}$ \\
\hline Ischæmic & 3 & $\begin{array}{l}\text { Mild } \\
\text { Moderate } \\
\text { Severe }\end{array}$ & $\begin{array}{l}\text { A. Fibr. } \\
\text { Ventricular T. } \\
\text { Nodal T. }\end{array}$ & 170 & $\underline{+}$ & $\underline{+}$ & $\begin{array}{c}\bar{t} \\
++\end{array}$ & \pm \\
\hline Hypertension & 2 & $\begin{array}{l}205 / 120 \\
230 / 110\end{array}$ & $\begin{array}{l}\text { Uncertain } \\
\text { A. Fibr. }\end{array}$ & $\stackrel{?}{160}$ & $\overline{-}$ & $\overline{-}$ & $\overline{-}$ & + \\
\hline Mitral stenosis & 1 & Moderate & A. Flutter & 160 & - & - & + & - \\
\hline Myopathy & 1 & Moderate & Atrial $\mathrm{T}$. & $\begin{array}{l}150 \\
210\end{array}$ & - & + & - & + \\
\hline Total & 10 & & & & & & & 4 \\
\hline
\end{tabular}

in six cases of mitral valve disease, even when the stenosis was mild [but only one case of mitral stenosis is shown in Table III]: it seems from this table that polyuria is not very likely to occur with aortic stenosis. Diuresis accompanied paroxysmal arrhythmia in both ischæmic and hypertensive heart disease.

Relation of Other Symptoms (Table IV). Angina pectoris does not inhibit polyuria.' In one patient with ischæmic heart disease and moderate angina of effort, paroxysmal atrial fibrillation provoked polyuria but not angina pectoris.

Syncope so far from inhibiting polyuria seems to make it more likely. One woman used to have attacks in bed at night and was in conflict whether to get up to pass water and lose consciousness, or stay where she was and face the consequences. Another woman said that when an attack started she might as well spend the next six hours sitting on the lavatory watching her limbs die, if indeed she was sufficiently conscious to sit anywhere or watch anything.

Acute left ventricular failure with pulmonary interstitial or alveolar œdema prevents the polyuria. In such cases diuresis may follow the termination of the attack and is then related to recovery from heart failure. Polyuria is not prevented by right-sided heart failure (see Table IV).

TABLE IV

Relation OF POlyURia AND OTHeR SyMPtoms

\begin{tabular}{|c|c|c|c|}
\hline Symptoms & & Polyuria & No diuresis \\
\hline 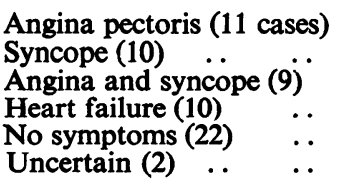 & $\begin{array}{l}\cdots \\
\cdots \\
\cdots \\
\cdots \\
\cdots\end{array}$ & $\begin{array}{r}5 \\
8 \\
6 \\
3 \\
10 \\
1\end{array}$ & $\begin{array}{r}6 \\
2 \\
3 \\
7 \\
12 \\
1\end{array}$ \\
\hline
\end{tabular}

Clinical Observations on the Polyuria Itself

The diuresis usually becomes manifest in 20 to 30 minutes but sometimes not for 60 minutes after the onset of the attack, the time interval tending to be remarkably constant for each case. One 
woman said that her geographical familiarity with London was conditioned by the whereabouts of public conveniences. If she developed an attack while she was out, she made a bee line for the nearest lavatory, on foot, by bus, or by taxi, according to its location, knowing that she would have to be there in precisely 30 minutes.

Another woman learned something of the occupants of houses near the bus-stops on her route between her home and her work. Her diuresis began rather soon after the onset of an attack and she was not infrequently caught out on the bus. She had made it her practice to get out at the next stop and to knock on the door of the most hospitable house. A man with an enlarged prostate was faced with a different sort of problem, for his diuresis often led to acute retention.

The majority of patients passed quantities of water every half hour or so for a variable period during the attack. When the tachycardia outlasted the polyuria, the diuresis ceased in $1 \frac{1}{2}$ to 8 hours.

\section{NATURe OF THE Polyuria}

The urine voided in a typical attack is considerable in quantity, pale in colour, of low specific gravity, and of low electrolyte content, i.e. it is a water diuresis with most of the features found in diabetes insipidus.

The increased volume of urine (mE per hour) and the increased output of sodium, and to a lesser extent of potassium, expressed in $\mathrm{mEq}$ per hour, during a paroxysm of atrial fibrillation are shown in Fig. 1 and in Table V. The increased output of urine and the decreased specific gravity in a paroxysm of atrial fibrillation in another patient are shown in Fig. 2. Fig. 3 from the same paroxysm shows a quick rise in the sodium and chloride, expressed as $\mathrm{mEq}$ per litre, followed by a much larger fall in both these and in the potassium: all these reached their nadir a little less than two hours after the attack had started. This was the same time as the nadir of the specific gravity, but

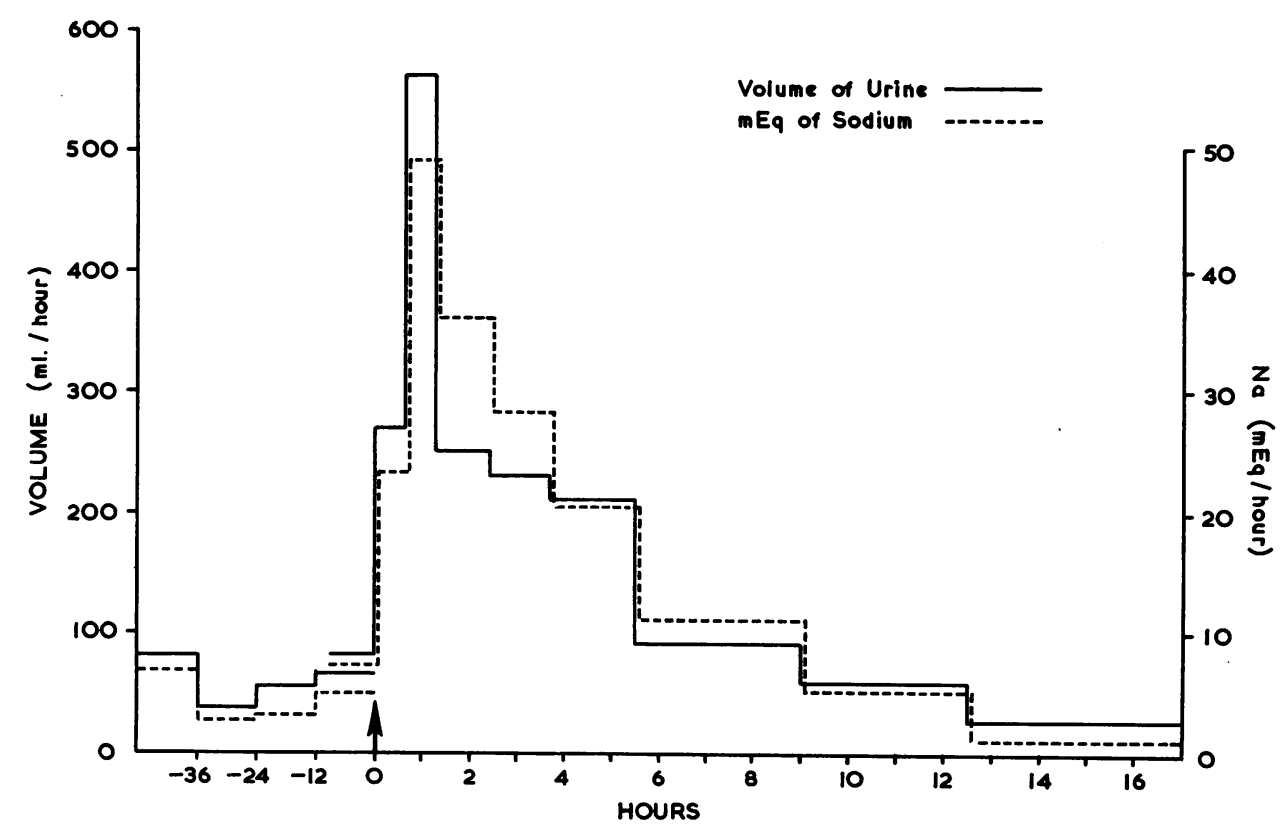

FIG. 1.-Chart showing the increased volume of urine per hour and the increased output of sodium in $\mathrm{mEq}$ per hour during an attack of paroxysmal atrial fibrillation that lasted 18 hours: the onset is indicated by an arrow. The increases started within 5 to 10 minutes, as was usual with this patient, and were considerable for $5 \frac{1}{2}$ hours, with a peak at about 1 hour. The urine had been measured and analysed for 48 hours, a week before this attack, and this is shown on the chart before the attack, as a control. From a woman, aged 60 , with hypertension and a cardiomyopathy. 
TABLE V

THE OUTPUT OF URINE (ML. PER HOUR) AND OF SODIUM AND POTASSIUM (AS MEQ PER HOUR) DURING A PAROXYSM

\begin{tabular}{|c|c|c|c|c|c|c|c|c|c|c|c|c|c|}
\hline & & & & $\begin{array}{l}\text { Normal* } \\
\text { a.m. }\end{array}$ & $\begin{array}{l}1.0 \dagger \\
\text { a.m. }\end{array}$ & $\begin{array}{l}1.40 \\
\text { a.m. }\end{array}$ & $\begin{array}{l}2.15 \\
\text { a.m. }\end{array}$ & $\begin{array}{l}3.20 \\
\text { a.m. }\end{array}$ & $\begin{array}{l}4.50 \\
\text { a.m. }\end{array}$ & $\begin{array}{l}6.30 \\
\text { a.m. }\end{array}$ & $\begin{array}{l}10.0 \\
\text { a.m. }\end{array}$ & $\begin{array}{l}1.30 \\
\text { p.m. }\end{array}$ & $\begin{array}{l}7.0 \dagger \\
\text { p.m. }\end{array}$ \\
\hline $\begin{array}{l}\text { Urine (ml./hour) } \\
\mathrm{Na} \text { (mEq/hour) } \\
\mathrm{K} \text { (mEq/hour) }\end{array}$ & $\begin{array}{l}\cdots \\
\cdots \\
\ldots\end{array}$ & $\begin{array}{l}\cdots \\
\cdots \\
\cdots\end{array}$ & $\begin{array}{l}\cdots \\
\cdots \\
\cdots\end{array}$ & $\begin{array}{l}57 \\
4 \cdot 2 \\
1 \cdot 8\end{array}$ & $\begin{array}{l}77 \\
6.8 \\
0.6\end{array}$ & $\begin{array}{r}270 \\
23 \cdot 3 \\
1 \cdot 5\end{array}$ & $\begin{array}{r}557 \\
49 \cdot 0 \\
2 \cdot 1\end{array}$ & $\begin{array}{r}250 \\
35 \cdot 8 \\
3 \cdot 1\end{array}$ & $\begin{array}{r}230 \\
28 \cdot 8 \\
2 \cdot 9\end{array}$ & $\begin{array}{l}210 \\
20 \cdot 5 \\
2 \cdot 6\end{array}$ & $\begin{array}{l}90 \\
11 \cdot 0 \\
2 \cdot 3\end{array}$ & $\begin{array}{l}60 \\
5 \cdot 4 \\
1 \cdot 7\end{array}$ & $\begin{array}{l}23 \\
1.0 \\
1 \cdot 0\end{array}$ \\
\hline
\end{tabular}

* Average for 48 hours, a week before attack.

$\dagger$ A paroxysm of atrial fibrillation started at 1.15 a.m. and finished at 7.30 p.m. the following day. See also Fig. 1 from the same patient.

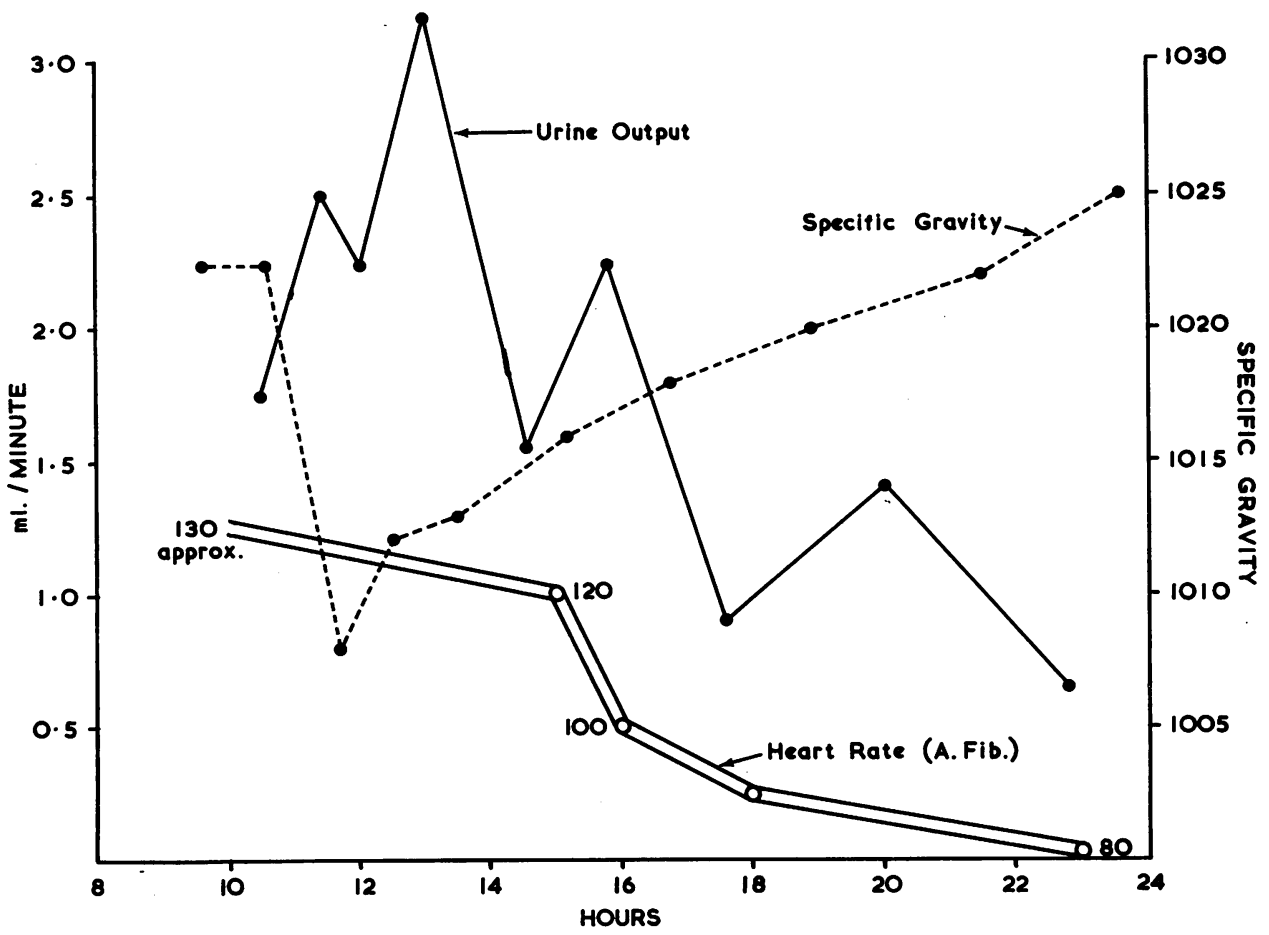

FIG. 2.-Chart showing the increased volume and diminished specific gravity of the urine during a paroxysm of atrial fibrillation that started at $9.50 \mathrm{a} . \mathrm{m}$. Though the paroxysm lasted 31 hours the patient ceased to be aware of it after about 4 hours when the ventricular rate fell from 120 and over towards $100 \mathrm{a}$ minute. As in most of his attacks, the diuresis came early and was mostly in the first 4 hours and finished in 7 hours. The peak of the volume output was at 3 hours and the nadir of the specific gravity at 2 hours. From a man, aged 63, with a heart that was otherwise normal: his attacks had recurred for 7 years and had been more frequent, almost once a week, for 3 years. 


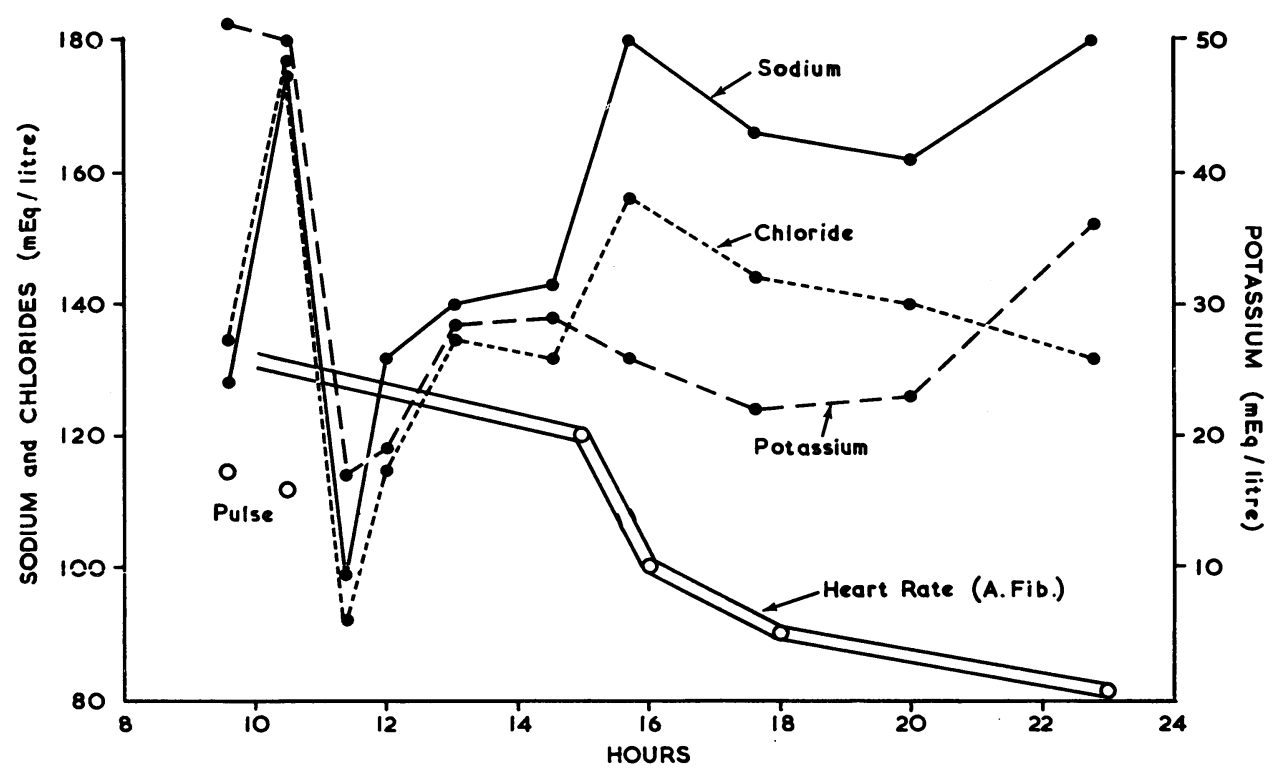

FIG. 3.-The changes in the electrolytes-sodium, chloride, and potassium-expressed as $\mathrm{mEq}$ per litre, from the same paroxysm as Fig. 2. After an immediate rise in sodium and chloride, both these and the potassium show a much larger fall reaching their nadir in a little less than 2 hours, at the same time as the lowest specific gravity but before the volume output of urine had reached its peak: this it did at 3 hours when the electrolytes were on their way back towards their normal. The effects of the diuresis were finished in less than 5 hours when the ventricular rate fell from 120 and over towards 100 a minute.

the volume of urine only showed a notch on its rise at this stage and continued to rise for more than an hour by which time the electrolyte concentrations were moving back towards their normal levels. Though this attack lasted 31 hours the patient ceased to be aware of it and the diuresis was practically finished after about 4 hours, when the ventricular rate fell from 120 and above towards 100 a minute.

At its highest, the volume of urine may be ten times as much as normally; and for much of the time while the diuresis persists, it may be three or four times as much (Table V). The specific gravity falls, e.g. from 1022 to 1008 (Fig. 2) or from 1030 to 1014 . With this, the electrolyte content falls, but for some substances much less than enough to balance the increased quantity of urine, so that in the case illustrated in Table $\mathrm{V}$ the outputs of sodium and chloride, expressed as $\mathrm{mEq}$ per hour were increased nearly as much as the output of urine, though the increase in the potassium excretion was much less. [No record is available to show how many paroxysms had been fully investigated in this way, but the illustrations given are from four paroxysms, full notes about which were in the folder. M.C.]

\section{Physiological Studies in Attacks}

As is widely recognized, the systolic and diastolic blood pressure and the pulse pressure commonly fall during a paroxysm. These changes are well shown in Fig. 4 where the blood pressure fell from about $110 / 57$ to $66 / 46 \mathrm{~mm}$. $\mathrm{Hg}$ in a paroxysm of tachycardia at the rate of 200 a minute. The frequency of syncope and near syncope bear further witness to this.

The cardiac output, however, has risen from 6 to 71 ./min. and from 3 to $51 . / \mathrm{min}$. in two cases in which we have been able to measure it consecutively, before, during, and immediately after an attack of supraventricular tachycardia provoked deliberately during cardiac catheterization, and stopped at will by the Valsalva manœuvre. The heart rates in these two attacks were 170 and 150 respectively. 


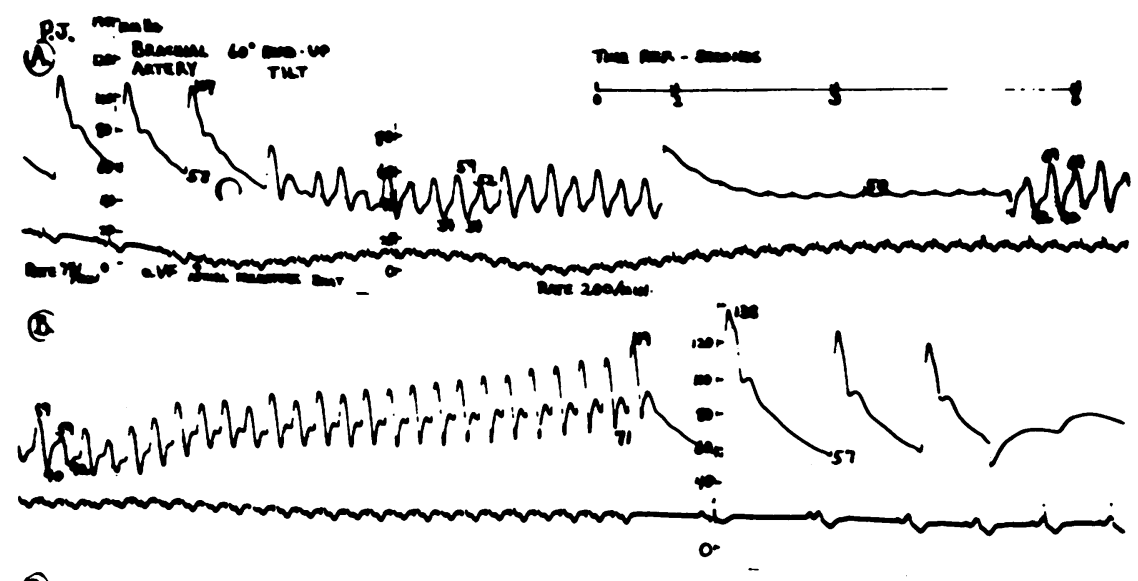

c.

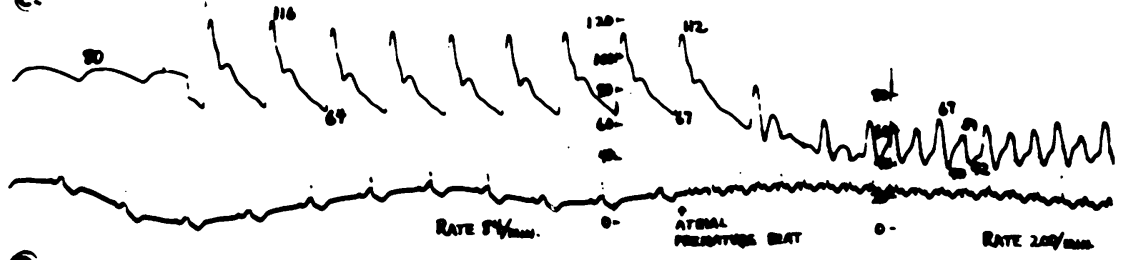

(6)

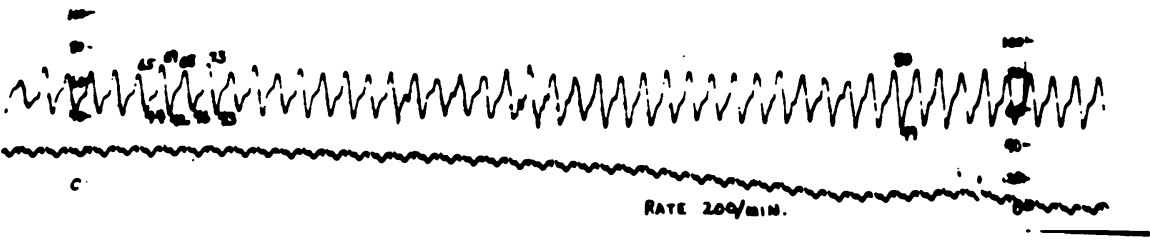

FIG. 4.-Fall of blood pressure in the brachial artery from about $112-107 / 57$ to $73-58 / 49-42$ during paroxysms of tachycardia at 200 a minute. (A) and (C) show the onset of paroxysms; (B) the end of a paroxysm; and (D) the continuation of a paroxysm.

On the other hand, a drop in cardiac output was found by Barcroft, Bock, and Roughton (1921) in one of the authors during a paroxysm of tachycardia. It is known to accompany atrial fibrillation, in the same patient (Broch and Müller, 1957) and in groups of patients (Ferrer et al., 1948; and Wade et al., 1952) and also atrial flutter (Harvey et al., 1955), especially in the presence of mitral stenosis.

The mean and pulse pressure in both the right and left atria rise during paroxysms of tachycardia. Fig. 5 shows a rise of pressure in the right atrium from $2 \mathrm{~mm}$. Hg to between $6 / 4$ and 9/3 mm. $\mathrm{Hg}$ (mean $5 \mathrm{~mm}$.) during a paroxysm of tachycardia at a rate of 200 a minute, at the same time that the pressure in the brachial artery is falling. Fig. 6 shows the rise in left atrial (pulmonary capillary) pressure in the same paroxysm, where it rose from about 5 to $14 \mathrm{~mm}$. $\mathrm{Hg}$.

This analysis indicates that a brisk water diuresis of limited duration frequently accompanies any form of paroxysmal arrhythmia with a heart rate over 120 beats a minute, particularly paroxysmal atrial fibrillation; that it is more profuse when the patient is recumbent; and that it tends to be prevented by left heart failure and by mitral valve disease. It has the hall marks of a transient diabetes insipidus, suggesting that it may be caused by inhibition of the antidiuretic hormone.

Strauss et al. (1951) found that the ingestion of two litres of normal saline was followed by a prompt diuresis only if the subject was recumbent, and attributed this to the shift of blood towards the thorax. In 1954, Gauer et al. showed that dogs subjected to negative pressure breathing had a moderate diuresis which also was attributed to a shift of blood into the thorax. Henry, Gauer, and 

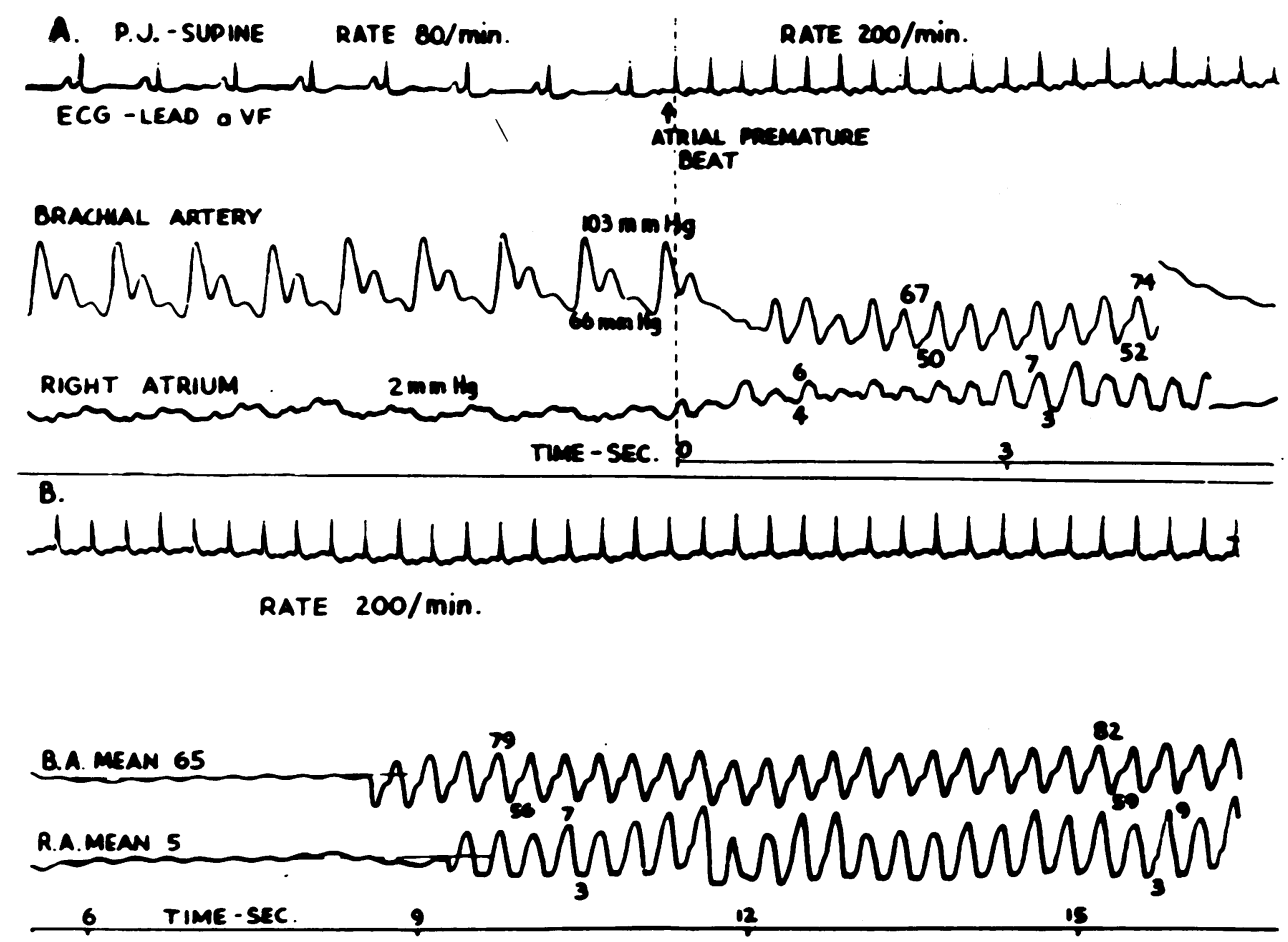

FIG. 5.-Brachial arterial and right atrial pressures in the same patient shown in Fig. 4: (A) before and at the onset of paroxysmal tachycardia at a rate of 200 a minute; and (B) during its continuation. The brachial arterial blood pressure fell from 103/66 to between $67 / 50$ and $82 / 59 \mathrm{~mm}$. Hg: and the right atrial pressure rose from $2 \mathrm{~mm}$. $\mathrm{Hg}$ (mean) to between $6 / 4$ and $9 / 3$ mm. $\mathrm{Hg}$ (mean $5 \mathrm{~mm}$.).

Reeves (1956) induced a large diuresis by distending a balloon in the left atrium, but not by constricting pulmonary veins: the diuresis was reduced by cold block of the vagus. Henry and Pearce (1956) concluded that when the left atrium is distended, stretch receptors send messages to the hypothalamus that result in inhibition of the antidiuretic hormone and lead to a water diuresis; and Pearce (1961) has summarized this work in discussing the regulation of the blood volume.

I was at first hesitant to accept the suggestion that this mechanism might explain the diuresis of the paroxysmal arrhythmias for the three following reasons. (1) I had no information what the left atrial pressure and volume were in paroxysmal lone atrial fibrillation and still have not for that matter. (2) Huge pulse pressures in both atria associated with paroxysmal nodal rhythm have not caused polyuria (Fig. 7). (3) The condition above all others that develops the greatest increase of pressure and volume in the left atrium during paroxysmal atrial fibrillation is mitral stenosis and this, even when mild, seems to prevent the response.

However, these objections are not insuperable and the hypothesis is attractive. Certainly the left atrial pressure rises appreciably in paroxysmal tachycardia, as my friend Dr. Saunders first showed me. It is possible that the low carotid pulse pressure tends to antagonize the diuresis by encouraging the secretion of aldosterone, and that this antagonistic effect is greater in cases of mitral stenosis and heart failure in which the carotid pulse pressure may be exceptionally low. Alternatively, an adequate renal blood flow may be necessary for the diuresis, and this condition may not be fulfilled in cases of heart failure and mitral stenosis. 
A. P.J. SUPINE

RATE Samin.

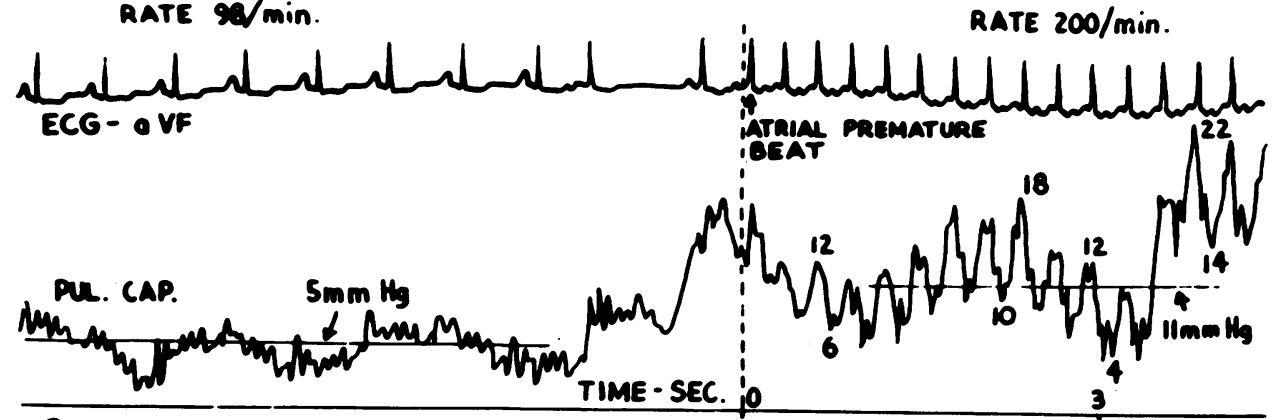

B.

RATE $200 / \mathrm{min}$.

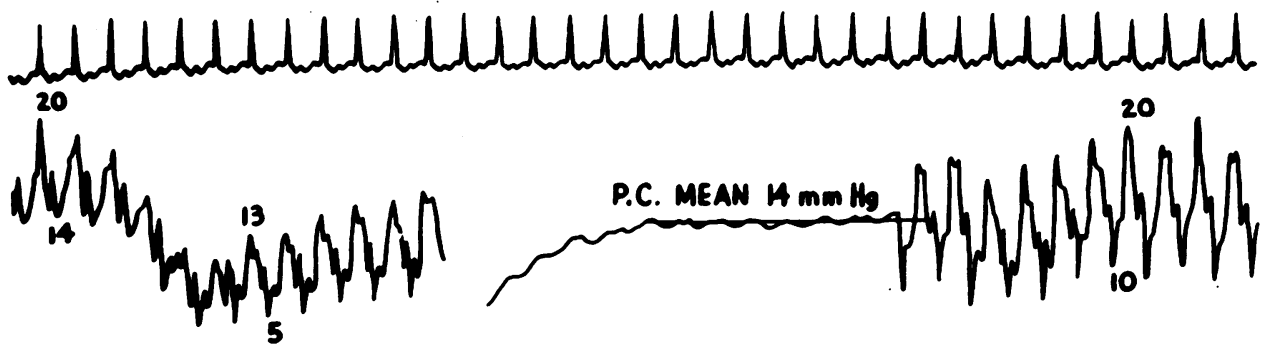

TIME - Sec. 6

9

12

15

Fig. 6.-The left atrial (pulmonary capillary) pressure in the same paroxysm of tachycardia that was recorded in Fig. 5. The mean pulmonary capillary pressure rose from about $5 \mathrm{~mm}$. to $14 \mathrm{~mm}$. $\mathrm{Hg}$, with the higher systolic and diastolic pressures varying from 12/4 to $22 / 14 \mathrm{~mm}$.
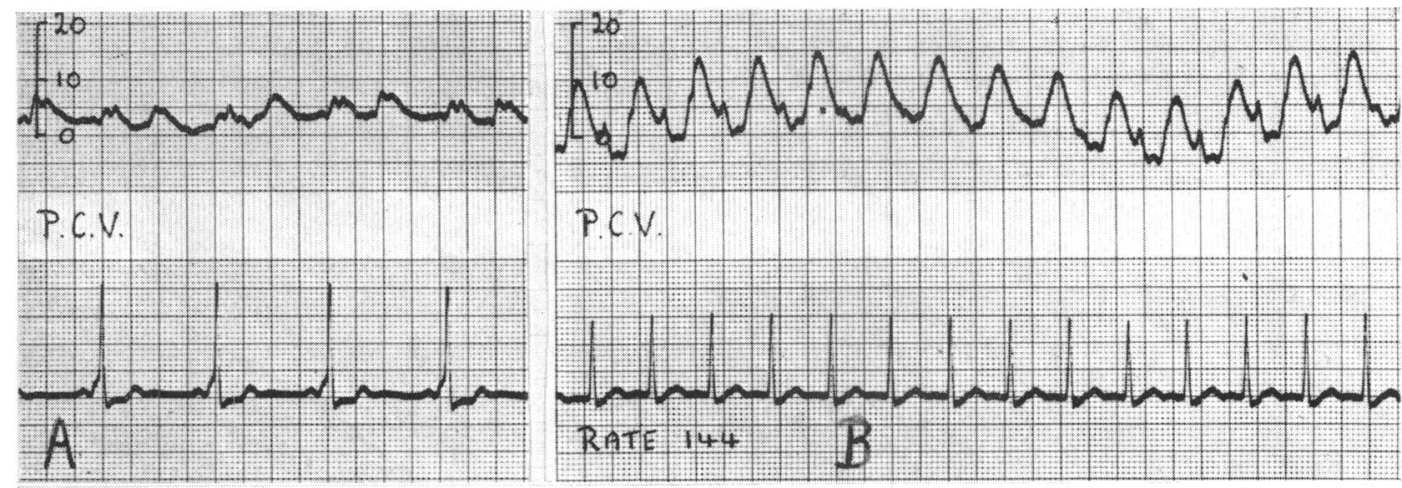

FIG. 7.-Rise of left atrial (P.C.V.) pressure with slower attack of supraventricular, probably nodal, paroxysmal tachycardia at 144 a minute. The pressure rose from about $7 / 2$ to about 10 to $15 / 2$ to $-4 \mathrm{~mm}$. $\mathrm{Hg}$, but in spite of this and the cannon waves there was no polyuria. From a woman, aged 22. 
This is the stage at which Wood's paper ends. The first three pages and the section on physiological studies in attacks are almost as he had written them, except for relating his text to the tables and adding many of the references; but the part between was in outline only and the Figures had to be found and something about them had to be added. I hope that the examples and figures that have been included are mainly as he would have chosen. With the paper were some notes (some in the writing of Dr. D. E. Saunders) about other work on the regulation of aldosterone secretion and suggestions about further observations that might be made during the polyuria, but they had not advanced far enough to include. The conclusions that follow are the published summary of the communication that Wood (1961) gave to the Cardiac Society.

\section{CONCLUSIONS}

Polyuria is associated with paroxysmal tachycardia and paroxysmal atrial fibrillation in over 40 per cent of cases with normal hearts and in many others, but rarely in those with mitral stenosis. The diuresis begins at once and becomes manifest in ten to thirty minutes: it may continue for several hours and, if still continuing then, stops immediately when the attack ends.

In paroxysmal atrial fibrillation, polyuria is usually associated with a ventricular rate between 130 and 170 a minute. In paroxysmal tachycardia with polyuria, the ventricular rate is usually between 180 and 280 -fast enough to cause syncope in several instances.

The urine voided is considerable in quantity, pale in colour, of low specific gravity, and low in electrolytes. It is obviously a water diuresis.

Physiological studies demonstrate a conspicuous rise in left atrial mean and pulse pressures in the circumstances described. Parallel studies on paroxysmal nodal rhythm with giant cannon waves in both left and right atria deny that an increased pulse pressure in either atrium or venous system is directly responsible.

The data suggest that polyuria associated with rapid heart rates is due to an increase in the volume of blood in the left atrium, and resembles the diuresis produced experimentally by inflating a balloon in that chamber.

I should like to thank Mrs. Wood for approving the publication of this paper. I am grateful to Miss Elizabeth Turner for finding the folder that contained much of this paper and some notes, and for helping me to look through Wood's slides to choose the Figures.

\section{REFERENCES}

Barcroft, J., Bock, A. V., and Roughton, F. J. (1921). Observations on the circulation and respiration in a case of paroxysmal tachycardia. Heart, 9, 7 .

Broch, O. J., and Müller, O. (1957). Hæmodynamic studies during auricular fibrillation and after restoration of sinus rhythm. Brit. Heart J., 19, 222.

Ferrer, M. I., Harvey, R. M., Werkö, L., Dresdale, D. T., Cournand, A., and Richards, D. W., Jr. (1948). Some effects of quinidine sulfate on the heart and circulation in man. Amer. Heart J., 36, 816.

Friedberg, C. K. (1949 and 1956). Diseases of the Heart, 1st ed. 1949; 2nd ed. 1956. Saunders, Philadelphia and London.

Gauer, O. H., Henry, J. P., Sieker, H. O., and Wendt, W. E. (1954). The effect of negative pressure breathing on urine flow. J. clin. Invest., 33, 287.

Harvey, R. M., Ferrer, M. I., Richards, D. W., and Cournand, A. (1955). Cardiocirculatory performance in atrial flutter. Circulation, 12, 507.

Henry, J. P., Gauer, O. H., and Reeves, J. L. (1956). Evidence of the atrial location of receptors influencing urine flow. Circulat. Res., 4, 85.

- , and Pearce, J. W. (1956). The possible role of cardiac atrial stretch receptors in the induction of changes in urine flow. J.Physiol. (Lond.), 131, 572.

Katz, L. N., and Pick, A. (1956). Clinical Electrocardiography: Part I. The Arrhythmias. Lea and Febiger, Philadelphia.

Pearce, J. W. (1961). A current concept of the regulation of blood volume. Brit. Heart J., $23,66$.

Strauss, M. B., Davis, R. K., Rosenbaum, J. D., and Rossmeisl, E. C. (1951). "Water diuresis" produced during recumbency by the intravenous infusion of isotonic saline solution. J. clin. Invest., 30,862 .

Wade, G., Werkö, L., Eliash, H., Gidlund, A., and Lagerlöf, H. (1)52). The hæmodynamic basis of the symptoms and signs in mitral valvular disease. Quart.J. Med., 21, 361.

White, P. D. (1951). Heart Disease, 4th ed. Macmillan, New York.

Wood, P. (1956). Diseases of the Heart and Circulation, 2nd ed. Eyre and Spottiswoode, London.

(1961). Polyuria in paroxysmal tachycardia. Brit. Heart J., 23, 457. 